\title{
DEFINIÇÕES DE TEMPERATURA EM FONTES DIDÁTICAS
} DEFINICIONES DE TEMPARATURA EN FUENTES DIDÁCTICAS

\author{
Jornandes Jesús Correia ${ }^{\mathrm{i}}$ \\ Universidade Estadual do Sudoeste da Bahia \\ jjcorreia@uesb.edu.br
}

\section{Resumo}

Dada a necessidade e a importância de um Professor conceituar e definir com clareza, o Grupo de Pesquisa "Didáticas das Ciências Experimentais e da Matemática (GDICEM)" do Museu Pedagógico Casa Padre Palmeira (MP), da Universidade Estadual do Sudoeste da Bahia (UESB), em uma de suas linhas temáticas de pesquisa, analisa a conceituação e definições de Grandezas e de Leis da Física em livros didáticos. Foi pesquisada a definição de Temperatura em 14 livros de Física de nível médio, em 14 livros de Física de nível superior, em Dicionários e em 6 sites da internet. Foram encontradas definições de Equilíbrio Térmico, de Calor e de Transferência de Energia Térmica, em detrimento a uma discussão qualitativa e epistemológica de Temperatura. Esta pesquisa foi fundamentada nas Concepções de Halbwachs. A definição de Temperatura mais encontrada nas fontes pesquisadas faz referência à Lei Zero da Termodinâmica, enquadrada na Concepção Heterogênea, em que a diferença de Temperatura é a Causa, tendo o Calor como Efeito; A definição de Concepção Homogênea aponta para a utilização de propriedades intrínsecas em nível molecular. A Concepção Batígena exige uma abordagem no campo da Mecânica Estatística, que envolveria Nível, Intensidade, Quantidade e Transferência de Energia Térmica. Foi detectada falta de discussões qualitativas no campo da epistemologia.

Palavras-chave: Livro didático. Conceito. Temperatura. Ensino de Física.

\section{Resumen}

Dada la necesidad y la importancia de un maestro conceptualizar y definir claramente, el Grupo de Investigación "Didática das Ciências Experimentais e Matemática (GDICEM)", do Museu Pedagógico Casa Padre Palmeira (MP),

\begin{tabular}{|l|l|l|l|l|l|l|} 
Revista RBBA & ISSN 23161205 & Vitória da Conquista & V. $6 \mathrm{n}^{\text {o }} 1$ & p. 201 a 220 & Junho/2017 \\
\hline
\end{tabular}


de la Universidade Estadual do Sudoeste da Bahia (UESB), en una de sus áreas temáticas de investigación, analisa los conceptos y definiciones de Grandeza y Leyes de la Física, en los libros didácticos. Se investigo la definición de Temperatura en 14 libros de Física de nivel medio, 14 libros de Física de nível superior, en diccionarios y 6 sitios de Internet. Fueron encontradas definiciones de Equilíbrio Térmico, de Calor e de Transferencia de Energía Térmica, en lugar de una discusión epistemológica cualitativa de Temperatura. Esta investigación se basa en concepciones de Halbwachs: la definición de Temperatura más comúnmente encontrada en las fuentes buscadas se refiere a la Ley Cero de la Termodinámica, enmarcado en la Concepción Heterogénea, donde la diferencia de Temperatura es la Causa, teniendo el Calor como Efecto. La definición de Concepción Homogénea apunta para el uso de propiedades intrínsecas a nivel molecular. La Concepcíon Batígena requiere un enfoque en el campo de la Mecánica Estadística, que implican Nivel, Intensidad, Cantidad y Transferencia de Energía Térmica. Se detectó falta de discusiones cualitativas en el campo de la epistemología.

Palabras clave: Libro didáctico. Concepto. Temperatura. Enseñanza de la Física.

\section{Introdução}

Nota-se, por meio do estudo do desenvolvimento histórico de conceitos científicos, conforme Gilbert, que houve uma árdua preparação das definições das grandezas físicas, desde suas primeiras concepções, ao ponto que se encontram aceitas pela Ciência. A leitura da história da conceituação de uma grandeza esclarece sobre a sua origem e facilita a sua compreensão. Gilbert defende a tese que o "único método legítimo, seguro, fecundo para preparar o espírito a receber uma hipótese física, é o método histórico":

Julgamos que o conhecimento das origens, da evolução e das mutações dos conceitos fundamentais de uma ciência faz tanto parte da história desta como o estudo das principais descobertas que marcam aquela evolução, bem como, ainda, o seu enquadramento nos condicionamentos sociais e econômicos, políticos e filosóficos, de cada época (1982, p. 39).

$\mathrm{O}$ registro das definições encontra-se em fontes documentais acadêmicas, tais como livros de texto, dicionários, enciclopédias, internet, artigos científicos entre outros. Nesse sentido, foram feitos levantamentos sobre a apresentação das definições de Temperatura em 
livros didáticos. O GDICEM já vem pesquisando a conceituação de grandezas físicas em livros didáticos, tais como as que foram pesquisadas grandezas como Trabalho de uma Força, Calor, Energia Interna, Entropia entre outras, a exemplo das pesquisas de Correia et al (2008a, 2008b, 2009, 2011, 2012, 2013a, 2013b, 2014, 2015a, 2015b), foi apontada a necessidade de conceitua-las com mais clareza, visto que essas grandezas apresentam grande utilização em outras áreas do conhecimento, principalmente em Saúde. Segundo Gilbert (1982), muitos cientistas possuíam um entendimento intuitivo, porém não conseguiam conceitua-las de maneira que as tornassem claras. Por outro lado, sem o empenho desses pesquisadores, a compreensão de fenômenos ou comportamentos físicos estaria mais dificultada. Dentre as grandezas pesquisadas, a Temperatura é a que apresenta relação com todas as que foram pesquisadas até então.

Temperatura é uma grandeza fenomenológica de Estado que está relacionada ao “estado" de 'quente' ou de 'frio'. A etimologia aponta que Temperatura vem do latim temperare, significando 'misturar corretamente, regular, moderar'. Misturar, neste caso, envolve pelo menos dois sistemas com estados térmicos distintos. O foco desse estado térmico é a Temperatura. Do ponto de vista qualitativo, Temperatura está associada ao estado de aquecimento de um sistema, enquanto que, do ponto de vista quantitativo, a sua medida está relacionada ao nível desse estado de aquecimento. Por outro lado, um estudo, que leva ao entendimento do real significado de Temperatura, envolve duas áreas de conhecimento da Física: A Termodinâmica Básica, em que Temperatura é analisada por meio de um Tratamento Macroscópico; A Mecânica Estatística, que está relacionada a um Tratamento Microscópico. A partir dessas duas vias é que se pode concluir que só faz sentido obter a definição de Temperatura para sistemas com mais de um corpo.

Nesse sentido, fizemos uma pesquisa sobre a apresentação das definições de Temperatura em Livros Didáticos, Dicionários e na Internet. Para fundamentar a nossa pesquisa, tomamos como referência a categorização das explicações de Francis Halbwachs (1977), em que as explicações de fenômenos podem ser feitas segundo três Concepções, a saber: Heterogênea, Homogênea e Batígena. A Concepção Heterogênea está fortemente relacionada aos Problemas da Casualidade, em que a explicação de um fenômeno parte do pressuposto da existência de uma consequência, o "Efeito" que, para justifica-lo baseia-se numa origem, a “Causa". Já a Explicação Homogênea toma como base características intrínsecas, tais como a natureza do sistema a ser definido. Por último, a Concepção Batígena 
explica um fenômeno, ou grandeza física, levando em consideração uma grande quantidade de variáveis, de modo a aprofundar a explicação da definição.

Foi apontado, por meio dos nossos resultados, que Temperatura ainda carece de uma discussão epistemológica, de modo a elucidar os textos que a apresentam, uma vez que não basta redigir uma frase como representação de uma definição pronta e acabada, se após a explanação ainda pairar dúvidas sobre o real significado do que foi supostamente definido.

\section{Definições de Temperatura em Livros Didáticos, em Dicionários e em Sites da}

\section{Internet: Análise e Discussões}

\subsection{Definições de Temperatura em livros do Nível Médio de Ensino}

Segue as definições encontradas em cada livro pesquisado e suas respectivas análises. Junior et al (1988:2-3) afirmam que

Podemos considerar a temperatura de um corpo como sendo a medida do grau de agitação de suas moléculas. Desta forma, supondo não haver mudança de fase, quando o corpo recebe energia térmica, suas moléculas passam a se agitar mais intensamente: a temperatura aumenta. [...] A situação final de equilíbrio que traduz uma igualdade de temperaturas dos corpos constitui o equilíbrio térmico. Assim, dois corpos em equilíbrio térmico possuem obrigatoriamente temperaturas iguais.

Merece destaque na definição acima: O grau de agitação térmica das moléculas não tem relação direta com a quantidade de energia térmica do corpo. Esta definição pode sugerir ao estudante que quanto maior a quantidade de energia térmica, maior a temperatura. A situação de Equilíbrio exige a existência de dois corpos, ou seja; enquanto que o que perdeu energia térmica poderá esfriar, enquanto que o que ganhou energia térmica poderá ficar mais aquecido. Durante o esfriamento de um e do aquecimento do outro, uma energia estará sendo transferida (Energia Térmica) do corpo mais quente para o corpo mais frio. Essa transferência cessará no instante em que os dois corpos atingirem um equilíbrio Térmico (à mesma temperatura). Essa energia em transferência, devido à diferença de temperatura entre os dois corpos é denominada de Calor.

Bonjorno et al (1993, p. 217) e Bonjorno et al (1998, p. 11), definem Temperatura da seguinte forma: “Temperatura é uma grandeza física que mede o estado de agitação das 
partículas de um corpo, caracterizando o seu estado térmico". Esta definição é extremamente concisa, mas não destaca as características da Temperatura.

Já Máximo e Alvarenga (2011, p. 12) são bastante superficiais ao apresentar a definição de temperatura: “[...] Em outras palavras, a temperatura de um corpo é uma propriedade relacionada com o fato de o corpo estar mais quente ou mais frio".

Ferrraro e Soares (1991, p. 179), por sua vez, definem temperatura como sendo "uma medida do grau de agitação das moléculas de um corpo". Embora esta afirmação esteja correta, sob o nosso ponto de vista, não foi apresentada a definição de Temperatura.

Parana (1998, p. 16) define com Temperatura com superficialidade, ao afirmar que “[...] temperatura é a grandeza que permite avaliar o grau de agitação térmica das moléculas de um corpo".

Omote (1985, p. 147) define Temperatura como "... a medida do grau de agitação térmica, isto é, uma função da energia cinética média das partículas constituintes da substância". De fato, temperatura representa a medida do grau de agitação térmica das moléculas constituintes de uma substância. Esta definição, apesar de ser concisa, está muito coerente.

Herskowicz et al (1993, p. 242) afirmam que “Temperatura é a medida que dá uma ideia do grau de agitação das partículas (átomos ou moléculas) que constituem o corpo, isto é, quanto maior o estado de agitação daquelas partículas, tanto maior será a sua temperatura". Embora este enunciado possa ajudar na compreensão de Temperatura, esta frase não constitui numa definição autoexplicativa.

Já Penteado e Torres (2005, p. 3) apresentam uma definição bastante coerente, a saber:

O movimento das partículas constituintes da matéria não é ordenado. Pelo contrário, ele é aleatório e, por isso mesmo, costuma ser chamado de agitação térmica molecular. A medida do grau de agitação das partículas constituintes de um corpo é feita por meio de uma grandeza denominada temperatura. Temperatura de um corpo é a medida do grau de agitação de suas partículas.

Yamamoto et al (2010, p. 12) afirmam que "Temperatura é a medida associada ao grau de agitação das partículas de um corpo ou sistema físico. Portanto, ela indica o nível de energia térmica média das partículas”. Merece destacar que essa agitação é no nível molecular. 
Já Boas et al (2010, p. 11) definem Temperatura como sendo "a grandeza que caracteriza o estado térmico de um sistema". De fato, Temperatura é um dos Estados Térmicos de um sistema, mas não apresenta uma discussão sobre Estado de um Sistema.

Silva e Filho (2010, p. 95) fazem referência a Temperatura da seguinte forma: "A temperatura de um corpo é uma medida do grau de agitação de seus átomos ou moléculas". Apesar de esta afirmativa ter caracterizado a Temperatura, não a definiu.

Fuke et al (1999, p. 10) são muito objetivos ao definirem Temperatura como sendo a "medida do nível de agitação térmica das moléculas ou medida do nível de energia térmica das partículas de um corpo ou sistema físico". Está vago, porque não esclarece sobre a “medida do nível de agitação térmica das moléculas".

Netto et al (1981, p. 18) afirmam que "[...] temperatura é a propriedade comum a dois ou mais corpos em equilíbrio térmico". Definiu apenas Equilíbrio Térmico.

Observamos que os livros de nível médio analisados apresentaram uma descrição sobre Temperatura com bastante superficialidade, ao mesmo tempo em que foram identificadas predominâncias das características Homogêneas nestas definições.

A seguir apresentaremos as definições de Temperatura apresentadas em livros de nível superior de ensino.

\title{
2.2 Definições de Temperatura em livros do Nível superior de Ensino
}

Resnick et al (2003, p. 207) afirmam que

\begin{abstract}
Quando dois sistemas estão em equilíbrio térmico, diz-se que eles têm a mesma temperatura. [...] É somente através deste argumento, baseado no equilíbrio térmico, que a noção de temperatura pode ser introduzida na física. A declaração da lei zero, em termos de temperatura, é a seguinte: Existe uma grandeza escalar chamada de temperatura, que é uma propriedade de todos os sistemas termodinâmicos em equilíbrio térmico se e somente se as suas temperaturas são iguais. Assim, a Lei Zero define o conceito de temperatura e permite que os termômetros possam ser construídos e utilizados.
\end{abstract}

A medida de uma grandeza ajuda a dimensiona-la, mas não deve ser o argumento suficiente para compreendê-la. Neste sentido, entendemos que a Lei Zero da Termodinâmica indica a existência da Temperatura, mas não a define. 
Nussenzveig (1981, p. 157) afirma que "A temperatura, conforme veremos adiante, está relacionada com a energia cinética média das partículas”. Esta fonte, com estas palavras, fez uma relação, mas não definiu Temperatura.

Oliveira (2005, p. 15) afirmou que:

Quando dois corpos são colocados em contato térmico, o corpo mais quente cede calor ao corpo mais frio. Enquanto as temperaturas forem diferentes, haverá um fluxo de calor entre eles. Depois de um certo tempo, as temperaturas se tornam iguais e o fluxo de calor cessa. A partir desse instante os corpos estão em equilíbrio térmico. Uma vez que um corpo esteja em equilíbrio térmico sua temperatura não se altera mais, a menos que seja perturbado.

Quanto a esta descrição, podemos destacar que Correia et al (2008a, 2009) apontam que um corpo não pode ceder Calor a outro e que não existe "fluxo de Calor"; o que se transfere é Energia Térmica. Vale destacar que: se algo foi transferido de um sistema a outro, é porque esse algo estava contido num dos sistemas; se existir fluxo de uma grandeza, essa grandeza deverá ser vetorial. Sabe-se que Calor não é Variável de Estado, nem uma Grandeza Vetorial. Em suma, esta fonte informa corretamente sobre as condições de Equilíbrio Térmico.

Wylen et al (2004, p. 25) apontam que há uma dificuldade em definir temperatura, a saber:

Devido a essas dificuldades para definir temperatura, definimos igualdade de temperatura. [...] Podemos dizer, portanto, que dois corpos possuem igualdade de temperatura se não apresentarem alterações em qualquer propriedade mensurável quando colocados em contato térmico.

Esta citação esclareceu que não iria apresentar a definição de Temperatura, mas a definição de Equilíbrio Térmico. Definir uma Grandeza Potencial constitui num desafio aos professores de Física, mas isso não é argumento para evitar a sua definição e medir apenas a sua diferença ou variação.

Hewitt (2011, p. 271) apresenta o enunciado que mais se aproxima de uma definição precisa de Temperatura, a saber:

Toda matéria - sólida, líquida ou gasosa - é composta por átomos ou moléculas em constante agitação. Em virtude desse movimento aleatório, os 
átomos ou moléculas da matéria possuem energia cinética. A energia cinética média dessas partículas individuais produz um efeito que podemos sentir - a sensação quente. A quantidade que informa quão quente ou frio é um objeto em relação a algum padrão é chamada de temperatura.

Acrescentaríamos a palavra "frio" na quinta linha da citação acima para tornar a definição mais precisa, a saber. Onde se lê "sensação quente", ler-se-ia "sensação de quente ou frio".

No volume 1, Mirshawka (1966, p. 1) apresenta a noção de Temperatura:

A noção mais imediata de temperatura é aquela que está ligada ao 'estado de aquecimento' e distinguimos de uma forma primitiva os diversos graus de aquecimento por meio do nosso sentido de tato.

Mais à frente, Mirshawka (1966, p. 5-6) aponta que a causa da transferência de Energia Térmica [...] é a temperatura: a energia se transfere do corpo de temperatura mais alta para a temperatura mais baixa. Se não houver diferença de temperatura não há transferência de energia sob a forma de calor. Como pode ser identificado nesta definição, foi estabelecida a condição para que haja transporte de um tipo de energia entre corpos a temperaturas diferentes, abrindo mão da definição de Temperatura. A dificuldade é identificar qual a "energia que se transfere" em meio a outras energias do sistema. Por conta dessa sutileza é que Correia et al (2008a, 2009) afirmam que "Calor é a energia em transferência entre dois sistemas, devido à diferença de Temperatura entre esses sistemas".

Pauli et al $(1979$, p. 7) afirmam ser a temperatura

... a propriedade que permite dizer se dois ou mais sistemas estão ou não em equilíbrio térmico. Dois ou mais sistemas em equilíbrio térmico apresentam a mesma temperatura; sistemas que não estão em equilíbrio térmico apresentam temperaturas diferentes. Note que este conceito é estritamente macroscópico.

Mais uma vez constatamos a insistência em definir Equilíbrio Térmico.

Zemansky (1978, p. 7) refere-se a Temperatura de um sistema como sendo a "propriedade que determina se um sistema se encontra ou não em equilíbrio térmico com outros sistemas". Observe que a diferença de Temperatura determina se há fluxo de uma grandeza vetorial proporcional ao gradiente da temperatura entre dois sistemas, mas não 
ocorreu a definição de Temperatura. É esse fluxo, contemplando um fator de proporcionalidade, que é determinado pela Lei de Fourier.

Sears (1979, p. 5) sugere um critério que facilita a compreensão de Temperatura, ou seja: "O primeiro passo para alcançar uma medida objetiva do senso de temperatura é estabelecer um critério de igualdade de temperatura”. Por outro lado, entendemos que igualdade de Temperatura, denominada de Equilíbrio Térmico, não define Temperatura. Alertamos que essa é uma condição da Lei Zero da Termodinâmica, que estabelece a condição de medida de uma grandeza, neste caso a Temperatura, mas que pode ser utilizada como qualquer outra grandeza; Com isso, a medida de uma grandeza não significa que a sua definição.

Oliveira (2005, p. 03) trata temperatura pelo Equilíbrio Térmico, a saber:

Quando um corpo quente é colocado em contato com um corpo frio, estabelece-se um fluxo de calor do primeiro para o segundo até o instante em que eles atingem o equilíbrio térmico. O equilíbrio térmico pode ser verificado por meio da medida da temperatura dos corpos. Se dois corpos tiverem a mesma temperatura então eles se encontram em equilíbrio térmico. Se diversos corpos estiverem em contato térmico entre si, eles estarão em equilíbrio térmico se todos tiverem a mesma temperatura.

Modificaríamos o texto acima substituindo a expressão "fluxo de calor", por transferência de Energia Térmica. Mesmo assim, após a correção, não indica que foi definida a grandeza Temperatura.

Willen et al (1975, p. 30) apresentam uma discussão interessante sobre a dificuldade de definir temperatura, a saber:

\begin{abstract}
Ainda que a temperatura seja uma propriedade bastante familiar, é difícil encontrar-se uma definição exata para ela. Estamos acostumados à noção de temperatura, pela sensação de calor e frio quando tocamos um objeto. Além disso, aprendemos logo, pela experiência, quando colocarmos um corpo quente em contato com um corpo frio, o corpo quente esfria e o corpo frio aquece. Se esses corpos permanecerem em contato por algum tempo, eles parecerão ter o mesmo grau de aquecimento ou resfriamento. Entretanto, reconhecemos também que nossa sensação não é bastante segura... Devido a estas dificuldades, definimos igualdade de temperatura.
\end{abstract}

Entendemos que os termos "calor" e "frio" que no texto acima estão relacionados com o senso comum, e não com a Física. 
Sears (1966, p. 503) define temperatura da seguinte forma:

Descreve-se Temperatura de um corpo, qualitativamente, pelo calor ou frio relativo. Ao tocar um corpo, nossa sensibilidade térmica nos permite estimar, grosseiramente sua temperatura, do mesmo modo que, por esforço muscular, podemos avaliar, embora sem precisão, a grandeza de uma força. É evidente que aquela sensibilidade tem alcance muito limitado e insuficientemente preciso para a engenharia, ou trabalhos científicos. Nas medidas de temperatura, precisa-se usar algumas propriedades físicas, mensuráveis, que com ela variem ...

Lamento, mas tenho que discordar desta definição apresentada por Sears (1966, p. 503). Esse é um dos riscos que se corre ao resumir a poucas palavras a definição de uma grandeza desta complexidade. Embora tenham sido apresentadas ideias gerais sobre Temperatura, devemos alertar que a medida da Temperatura não avalia o Calor. A Temperatura de um corpo ou sistema indica o nível da quantidade de Energia Térmica desse corpo ou sistema. O Calor é encontrado entre dois corpos, na fronteira entre eles, e não dentro de um deles, enquanto que Temperatura, microscopicamente, é a representação de uma medida dentro dessa fronteira. Entendemos que a expressão "calor ou frio", neste contexto, só deveria ser usada no senso comum.

Costa foi, sob a nossa óptica, a fonte consultada que apresentou a melhor redação para a definição de Temperatura, inclusive identificando-a como Variável de Estado. Também, por meio da leitura dessa fonte é que acreditamos que foi apresentada uma clara diferença entre Energia Térmica, Calor e Temperatura, inclusive com muita propriedade. Por exemplo: Costa (1971, p. 34) define o Estado de um Sistema como sendo:

O estado de um sistema, do ponto de vista termodinâmico, fica de uma maneira geral caracterizado pelas chamadas variáveis (arbitrárias ou funções) de estado. Estas variáveis, que por si só determinam os equilíbrios aludidos acima, são propriedades inerentes ao próprio sistema e tomam o nome de propriedades ou coordenadas termodinâmicas.

Salientamos que o texto fez referência ao Equilíbrio e às condições do Equilíbrio Termodinâmico. Ou seja, cada equilíbrio deve atender à uma condição de equilíbrio para que a mesma seja definida como uma "propriedade de um sistema". O próprio introduz noções gerais de Temperatura por meio do seguinte texto:

\begin{tabular}{l|l} 
Revista RBBA & Revista Binacional Brasil Argentina
\end{tabular} 
Temperatura, de acordo com considerações puramente termodinâmicas, é, como qualquer outra característica de Estado, determinada por meio de observações experimentais dos corpos como todo, enquanto que, de acordo com a Teoria Cinética, pode a mesma ser avaliada a partir da energia cinética média das moléculas (COSTA, 1971, p. 16).

Essa mesma fonte, alvo da nossa pesquisa, afirmaria ainda que

A Cinética usa, portanto, um processo microscópico, enquanto que a Termodinâmica vale-se de um método essencialmente macroscópico para verificar transformações, estabelecer leis, basear princípios dos fenômenos, objeto dos seus estudos (COSTA, 1971, p. 16).

Ofertando um esclarecimento sobre uma opção de abordagem da obtenção diferença de temperatura por meio da Mecânica Estatística, a saber: “...a Teoria Cinética de Boltzmann procurou dar interpretação mecanística dos fenômenos, conceitos, propriedades e princípios Termodinâmicos, lançando assim as bases da moderna Mecânica Estatística” (Op. Cit).

Voltando a tratar de Temperatura o faz da seguinte forma:

A temperatura é o conceito físico que nos permite medir o estado térmico de um sistema, estabelecendo a sua maior ou menor capacidade de transmitir calor, ou ainda, de acordo com a teoria cinética, a energia cinética média de suas moléculas (Op. Cit. p. 35).

Ainda cabe comentar que não existe "transmissão de Calor" e que a capacidade de transmitir energia térmica não está na Temperatura de um sistema, e sim na diferença de Temperatura entre dois sistemas. Observando esse detalhe, como correção, esse mesmo autor, fazendo uso da expressão "transferência de Calor", ainda é de nosso entendimento que essa fonte é a que aborda sobre Temperatura com maior clareza. Há, nessa mesma fonte (COSTA, 1971, p. 28), uma definição muito concisa de Energia, a saber:

Todas nossas percepções sensoriais estão ligadas à entidade física energia, a qual, dentro do campo da Termodinâmica, assume importância fundamental. Energia é a capacidade virtual que apresentam os sistemas materiais de produzirem trabalho mecânico (força em potência na filosofia de Aristóteles).

Entendemos que, é no campo da Termodinâmica que se encontra a necessidade de atribuir Energia a um sistema material, pois é por meio da variação das propriedades dos 
sistemas que a Energia é mensurada. Entretanto, Costa ainda apresenta uma definição de Energia atribuída a Lord Kelvin e Planck:

Energia de um sistema material em um certo estado, referido a um estado normal escolhido convenientemente, é igual à soma algébrica dos equivalentes mecânicos de todos os efeitos exteriores aos sistemas, quando ele passa de um modo qualquer do primeiro para o segundo estado (Op. Cit., p. 28).

Vindo a concluir a definição de Energia quando fez o seguinte comentário:

É interessante salientar que esta capacidade, embora não possa, em grande parte dos casos, ser percebida diretamente e apresente uma natureza complexa e indeterminada, constitui algo real cuja existência pode ser comprovada com toda exatidão pelos efeitos que a produz (Op. Cit. p. 29).

Fica agora mais fácil distinguir Energia Térmica de Calor, uma vez que Energia Térmica é uma Energia-Estado. Energia Térmica foi definida da seguinte forma num site da internet

Energia térmica é uma forma de energia que está diretamente associada à temperatura absoluta de um sistema, e corresponde classicamente à soma das energias cinéticas microscópicas que suas partículas constituintes possuem em virtude de seus movimentos de translação, vibração ou rotação ${ }^{\text {ii }}$.

Observe que as definições de Equilíbrio Térmico, de Calor e de Energia Térmica exigem o emprego do termo "Temperatura". Por outro lado, para definir Temperatura, a maioria dos livros consultados para esta pesquisa, tomou como referência o Equilíbrio meio de avaliação macroscópica..

Observou-se, nos livros de Nível Superior, textos mais extensos e mais elucidativos em relação aos livros de Nível Médio de Ensino.

\subsection{Definições de Temperatura em Dicionários}

Segundo Magalhães et al (1973, p. 613), Temperatura é a

Qualidade dos corpos, percebida pelo tato, a qual nos dá o estado de aquecimento ou estado térmico dos mesmos. A temperatura de um corpo é o 
seu estado térmico considerado em relação ao seu poder de comunicar calor a outros corpos (James Clerk Maxwell, Theory of Heat).

A temperatura mede a velocidade e a natureza do movimento molecular; informa-nos sobre a intensidade da energia, nada nos dizendo, porém, da quantidade de energia (Faires).

Propriedade que indica se um corpo está ou não em equilíbrio térmico com outros corpos.

Podem-se observar três definições distintas. A terceira é a que destoa das demais, porque para obter a medida da temperatura de um sistema não há necessidade de comparar se ele está mais quente ou mais frio que outro. Mesmo assim, estas as definições objetivas, comparadas com outras que foram encontradas em fontes do nosso estudo. A condição para que dois corpos em contato não permita troca de energia térmica entre eles é que eles estejam em Equilíbrio Térmico. Corpos com essa condição de equilíbrio têm uma mesma propriedade térmica em comum denominada de Temperatura.

Por outro lado, o dicionário Aurélio (FERREIRA, 1993) não apresenta definições coerentes de Temperatura. Uma das definições de Temperatura, apresentada por Aurélio, é que a "quantidade de calor que existe no ambiente, resultante da ação dos raios solares". Podem ser apontados vários problemas nesta definição. Um deles, e muito comprometedor, é que temperatura não pode ser "Quantidade de Calor", porque Calor é uma espécie de Energia em movimento de um sistema a outro, diminuindo a energia térmica do sistema que a perdeu e aumentando a energia térmica do que a ganhou, e que Temperatura não é quantidade de energia. Outro problema é que Calor não pode estar contido num ambiente, uma vez que o Calor é medido na fronteira de um 'ambiente'. A expressão "ação resultante dos raios solares" é devido à energia existente no espectro da onda proveniente do Sol, que ao ser absorvida pela Terra é transformada em Energia na faixa do Infravermelho (Energia Térmica) e, por conta da Atmosfera Terrestre, essa energia fica aprisionada na Terra, tornando-a aquecida. Outra definição apresentada por Aurélio é que Temperatura é a "Quantidade de Calor existente num corpo". Isto também não é verdade, porque o Calor não pode existir num corpo. A definição menos problemática apresentada por Aurélio é a que afirma que Temperatura é uma "Grandeza Termodinâmica intensiva comum a todos os corpos que estão em equilíbrio térmico". Se por um lado não compromete, por outro não define Temperatura. Grandezas intensivas são aquelas que não dependem da massa do sistema: um corpo, a uma determinada temperatura é dividido em duas partes desiguais; Cada pedaço da divisão terá, necessariamente, a mesma temperatura do corpo antes da divisão. As duas novas partes do 
corpo, neste caso, estarão em equilíbrio térmico. Observe que esta definição reporta ao Equilíbrio Térmico, que é uma tendência na redação das definições que foram encontradas para Temperatura nas fontes pesquisadas.

\subsection{Definições de Temperatura na Internet}

Considerando que o uso de computadores para obter informações já se tornou uma prática sem precedestes, é que fizemos uma busca das definições de Temperatura em sites de internet. Faremos aqui uma breve discussão de cada uma das definições que foram alvo da nossa pesquisa.

Em um dos sites pesquisados encontramos que "Temperatura é a grandeza que caracteriza o estado térmico de um corpo ou sistema"iii. Embora Temperatura seja realmente uma Variável de Estado, esta “definição” apenas fez uma afirmativa, sem defini-la.

Em outro site, encontramos que:

Temperatura é a grandeza física associada ao estado de movimento ou à agitação das partículas que compõem os corpos. No cotidiano é muito comum as pessoas medirem o grau de agitação dessas partículas através da sensação de quente ou frio que se sente ao tocar outro corpo. No entanto não podemos confiar na sensação térmica. Para isso existem os termômetros, que são graduados para medir a temperatura dos corpos ${ }^{\text {iv }}$.

O curioso que é este texto faz referência às características microscópicas de uma grandeza, mas aponta para a medida por meio de avaliação macroscópica.

Outro site apresenta a seguinte definição: "Temperatura é uma grandeza física que indica a intensidade de calor ou frio de um corpo, de um objeto ou do ambiente, em geral medida por meio de um termômetro"v. Entendemos que esta publicação não definiu Temperatura e que temperatura só pode ser compreendida como uma grandeza que indica a intensidade de calor se forem obtidas as temperaturas de dois corpos em contato.

Em outro site, Temperatura foi definida como:

Temperatura é uma grandeza física que mensura a energia cinética média de cada grau de liberdade de cada uma das partículas de um sistema em equilíbrio térmico.

Em sistemas constituídos apenas por partículas idênticas essa definição associa-se diretamente à medida da energia cinética média por partícula do sistema em equilíbrio térmico. A presente definição é análoga a afirmar-se que a temperatura mensura a energia cinética média por grau de liberdade de 
cada partícula do sistema uma vez consideradas todas as partículas de um sistema em equilíbrio térmico em um certo instante. A rigor, a temperatura é definida apenas para sistemas em equilíbrio térmico ${ }^{\text {vi }}$.

Entendemos que esta definição é a que mais retrata o real significado de Temperatura. Porém, pode ser notada uma sutileza no primeiro parágrafo desta definição, podendo sugerir ao leitor que Temperatura mensura o quantitativo da Energia Cinética Média. Advertimos que Temperatura mede o nível dessa Energia Cinética Média. Por outro lado, a expressão matemática que a Teoria Cinética apresenta para relacionar Temperatura Absoluta com Energia Cinética Média não trata desse detalhe conceitual.

Já outro site apresenta a seguinte definição:

\begin{abstract}
A temperatura pode ser definida como uma representação numérica, para o estado de agitação das partículas que formam os corpos. Quanto mais agitadas as partículas maiores a temperatura. Criamos um conceito popular de temperatura, dividindo em quente ou frio, mas as sensações de temperatura podem variar muito de pessoa para pessoa. Algo que é quente para mim, pode ser frio para você. Para evitar problemas com essa definição de quente ou frio, devemos consultar os termômetros ${ }^{\text {vii }}$.
\end{abstract}

Embora essa última definição deixe subjetivo a existência de Estados e que Temperatura pode ser um desses Estados, mesmo assim esta definição está muito coerente. Vale a pena ressaltar que é microscópica essa agitação relacionada à Temperatura e que não deve ser relacionada, necessariamente, com a agitação macroscópica.

Finalmente, um site pesquisado apresenta que "Do latim temperature, a temperatura é uma grandeza física que exprime o nível de calor, seja de um corpo, de um objeto ou do ambiente. Essa grandeza está associada à noção de frio (menor temperatura) e quente (maior

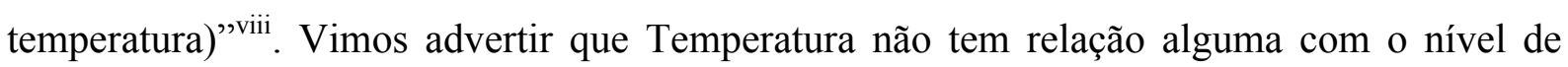
Calor e que não deveria sugerir que Calor pode estar contido em um sistema. A Lei de Fourier estabelece que o Calor é a Energia Térmica em transferência entre dois sistemas e que o Calor é proporcional ao fluxo do gradiente da Temperatura entre esses dois sistemas. Com isso, o Calor é uma Função de Transformação, enquanto que a Temperatura é uma Variável de Estado de um Sistema. Sendo assim, dois sistemas em equilíbrio térmico e com temperaturas altíssimas poderão não permitir a existência do Calor na fronteira entre eles. 


\section{Conclusão}

Observe que a Lei Zero da Termodinâmica não define Temperatura. Essa Lei estabalece as condições do Equilíbrio Térmico, como no exemplo que se segue: Considere a existência de uma grandeza padrão A, que pode ser massa ou comprimento. Considere agora um medidor (B), que está aferido com um valor padrão (A). Uma segunda grandeza (C) pode ser medida a partir de B. É obvio que o valor obtido de $\mathrm{C}$, por intermédio de $\mathrm{B}$, está em consonância com algum valor de A. Insistimos nesta observação porque a medida de $C$, que está igualada a A e a B, não indica, nem garante, a definição de C. Nesse sentido, parte dos livros de Nível Médio de Ensino que foi analisada nesta pesquisa não definiu Temperatura, mas Equilíbrio Térmico.

Algumas definições atribuíram Temperatura ao Calor. Observe que Calor é Energia em estado de transferência entre dois sistemas devido à diferença de Temperatura entre esses dois sistemas. Por outro lado, o Calor foi o escopo de uma pesquisa de outro artigo nosso (CORREIA, 2008a, 2009), em que também foram pesquisadas várias fontes.

Ora a Temperatura apareceu nos livros pesquisados associados à Energia Térmica. Energia Térmica é a Energia intrínseca de um corpo devido a sua Temperatura acima do Zero Absoluto.

Identificamos, na lógica estabelecida pelos construtos das grandezas físicas, que as grandezas Termodinâmicas definidas por Costa (1971) foram as que apresentaram maior claresa, comparadas às definiões encontradas nas outras fontes pesquisadas, porque entendemos que as definições encontradas em Costa (1971) estão adequadas à Concepção de Definição Batína de Francis Halbwachs.

Finalizamos a nossa pesquisa com a citação de um trecho de Gilbert (1982, p. 39)

Será ainda recomendável inserir por vezes referências particulares à vida de alguns cientistas que pode dar-nos sugestões de comportamentos exemplares - ou não. Aproveitaremos entretanto certos casos para mostrar como os maiores gênios erram facilmente, logo que se afastam da matéria que dominam, pelo que será sempre perigosa a invocação de suas opiniões sobre outras matérias (isto sim, como é obvio, não se aplica apenas aos cientistas...) Compreenderemos assim melhor as reservas que devem ser postas às manipulações, por exemplo de simples professores universitários, que nem são gênios; quando thes convém, certos meios apresentam as suas opiniões como decisivas, como se fossem fatos! 


\section{Referências}

BÔAS, N. V.; DOCA, R. H.; BISCUOLA. G. J. Física, Vol. 2. $1^{\text {a }}$ Edição. São Paulo. Editora Saraiva: 2010.448 pp.

BONJORNO, R. A.; BONJORNO, J. R.; BONJORNO, V.; RAMOS, C. M. Física Fundamental: $2^{\circ}$ grau: volume único. São Paulo. Editora FTD: 1993. 495 pp.

BONJORNO, R. A.; BONJORNO, J. R.; BONJORNO, V;. RAMOS, C. M. Temas de Física: Termologia, óptica geométrica, ondulatório. Vol. 2, $1^{\text {a }}$ Edição. São Paulo. Editora FTD: 1998. $374 \mathrm{pp}$.

CORREIA, J.; MAGALHÃES, L. D. R.; LIMA, L. S. Obstáculos Epistemológicos e o Conceito de Calor. Scientibus Série Ciências Físicas 04: 1-10, 2008a. Disponível em: < http://dfis.uefs.br/sitientibus/vol4/Jornandes-Main-SPSS2008.pdf>. Acesso em: 05 set. 2016.

CORREIA, J.; MAGAlHÃES, L. D. R.; LIMA, L. S. Obstáculos Epistemológicos Envolvidos no Conceito de Calor. In: XXVI ENCONTRO DE DO NORTE-NORDESTE. 2008. Recife (PE). Resumos... Recife, Sociedade Brasileira de Física; 2008b. p. 168. Disponível em: <http://www.sbfisica.org.br/ efnne/xxvi/XXVI_EFNNE_RESUMOS.pdf $>$. Acesso em 05 set. 2016.

CORREIA, J.; MAGALHÃES. Obstáculos Epistemológicos na transposição didática do Calor, In. IX Cólóquio do Museu Pedagógico. (ISSN 2175-5493), Vitória da Conquista (BA), Anais. Vitória da Conquista. Museu Pedagógico Casa Padre Palmeira. 2009. vol. 8, $\mathrm{N}^{\mathrm{o}} 1$. 727-740. 2009. Disponível em: $<$ http://periodicos.uesb.br/index.php/cmp/article/viewFile/3574/3265>. Acesso em: 05 set. 2016.

CORREIA, J.; JOSÉ, W. D. O conceito de trabalho de uma força em livros didáticos, In: IX Colóquio do Museu Pedagógico (ISSN 2175-5493), Vitória da Conquista (BA), Anais. Vitória da Conquista. MUSEU PEDAGÓGICO CASA PADRE PALMEIRA. 2011. vol. 9, No 1. 727-740 2011. p. $\quad$ Disponível em: < http://periodicos.uesb.br/index.php/cmp/article/viewFile/2663/2330>. Acesso em: 05 set. 2016.

CORREIA, J.; JOSÉ, W.; BARROS, S. T. S.; OLIVEIRA, L. M. O Conceito de Entropia nos Livros de Física de Nível Médio de Ensino, In: XXX ENCONTRO DE FÍSICOS DO NORTE-NORDESTE, 2012. Salvador (BA). SOCIEDADE BRASILEIRA DE FÍSICA Resumos... $\quad 2012 . \quad$ Salvador 2 Disponível $<$ https://sec.sbfisica.org.br/eventos/efnne/xxx/sys/resumos/R0746-1.pdf $>$. Acesso em: 05 set. 2016.

CORREIA, J.; JOSÉ, W. D. O conceito de entropia e as leis da termodinâmica em livros didáticos de física. In. X CÓLÓQUIO DO MUSEU PEDAGÓGICO (ISSN 2175-5493), vol. 10, $\mathrm{N}^{\mathrm{o}}$ 1, 2013a. Vitória da Conquista (BA). MUSEU PEDAGÓGICO CASA PADRE PALMEIRA. 2013. Anais. Vitória da Conquista Disponível em: < http://periodicos.uesb.br/index.php/cmp/article/viewFile/3008/2717>. Acesso em: 05 set. 2016. 199-212p. 
CORREIA, J.; SOUZA, J. S; SANTOS, C. C. Definições de Temperatura em Livros didáticos de Física, In. XXXI ENCONTRO DE FÍSICOS DO NORTE-NORDESTE, 2013b, Campina Grande (PB). Resumos... Campina Grande, SOCIEDADE BRASILEIRA DE FÍSICA, 2013. Disponível em: <https://sec.sbfisica.org.br/eventos/efnne/xxxi/sys/resumos/R0551-1.pdf>. Acesso em 05 set. 2016.

CORREIA, J.; ORTIGOZA, L. V. O conceito de conservação de energia em livros didáticos (Uma análise histórico-didática), In: XXXII Encontro de Físicos do Norte e Nordeste, 2014. João Pessoa (PB). Resumos... João Pessoa, SOCIEDADE BRASILEIRA DE FÍSICA; 2014. Disponível em: < https://sec.sbfisica.org.br/eventos/efnne/xxxii/sys/resumos/R0336-1.pdf $>$. Acesso em: 05 set. 2016.

CORREIA, J.; ORTIGOZA, L. V. O conceito de conservação de energia em livros didáticos: Uma análise histórico-didática, Revista Binacional Brasil-Argentina, Vol. 4, $\mathrm{N}^{\mathrm{o}}$ 2, p. 91103. 2015A. Disponível em: $<$ http://periodicos.uesb.br/index.php/rbba/article/view/5649/5377>. Acesso em: 05 set. 2016.

CORREIA, J.; ORTIGOZA, L. V. O conceito de conservação de energia em livros didáticos: Uma análise histórico-didática, In. XI COLÓQUIO DO MUSEU PEDAGÓGICO, 2015b. MUSEU PEDAGÓGICO CASA PADRE PALMEIRA, Vol. 19, № 2,. 2015. Disponível em: $<$ http://periodicos.uesb.br/index.php/cmp>. Acesso em: 05 set. 2016. p. 4095-4108

COSTA, E. C. da. Física Industrial. Tomo I, Termodinâmica, $1^{\text {a }}$ Parte. Porto Alegre. Editora Globo. 1971. 262 pp.

FERRARO, N. G.; SOARES, P. T. Física Básica: $2^{\circ}$ grau. $4^{\mathrm{a}}$ Edição. São Paulo. Editora Atual: 1991. $444 \mathrm{pp}$.

FERREIRA, Aurélio Buarque de Holanda. Novo Dicionário Aurélio da Língua Portuguesa. Rio de Janeiro: Editora Nova Fronteira, 1993. 1838 pp

FUKE, L. F.; SHIGEKIYO, C. T.; YAMAMOTO, K. Os Alicerces da Física - Termologia, óptica, ondulatória, volume 2. 13 ${ }^{\mathrm{a}}$ Edição. São Paulo. Editora Saraiva: 1999. 463 pp.

GILBERT, A. Origens Históricas da Física Moderna: Introdução Abreviada. Fundação Calouste Gulbenkian. Lisboa. Portugal, 1982. 451 pp.

HALBWACHS, F. Sobre los problemas de la causalidad física. In. MONOD et al. (eds). Epistemogía y marxismo, Barcelona: Ediciones Martinez Roca, 1974, Pp. 45-70. Apud CINDRA, J. F.; TEIXEIRA, O. P. B. Calor e temperatura e suas explicações por intermédio de um enfoque histórico. In. Martins, R. A.; MARTINS, L. A. C. P.; SILVA, C. C.; FERREIRA, J. M. H. (EDS) Filosofia e história da ciência no Cone Sul: $3^{\circ}$ Encontro, Campinas: AFHIC, 2004, (ISBN 85-904198-1-9). Pp. 240-248.

HERSKOWICZ, G.; PENTEADO, P. C. M.; SCORLFARO, V. Curso Completo de Física, volume único. $1^{\text {a }}$ Edição. São Paulo. Editora Moderna: 1993. 631 pp.

HEWITT, P. G. Física Conceitual. Tomo 1, $1^{\text {a }}$ Edição. São Paulo. ARTMED EDITORA S.A: $2011.732 \mathrm{pp}$. 
JUNIOR, F. R.; SANTOS, J. I. C.; FERRARO, N. G.; SOARES, P. A. T. Os Fundamentos da Física, Vol. 2. $3^{\text {a }}$ Edição. São Paulo. Editora Moderna: 1988. 346 pp.

MAGALHÃES, A.; ZAMBRANO, R. S.; SIECZKOWSKI. Dicionário de Física. Editora Globo. 1973. Porto Alegre. 668 pp.

MÁXIMO, A.; ALVARENGA B. Curso de Física, volume 2. $1^{\text {a }}$ Edição. São Paulo. Editora Scipione: 2011.360 pp.

MIRSHAWKA, V. Termologia. Volume 1. São Paulo: Nobel, 1966. 318 pp.

MIRSHAWKA, V. Termologia. $1^{\text {a }}$ Edição. São Paulo. Nobel, 1966. 157 pp.

NETTO, P. H.; O. C. RODRIGUES O. Fundamentos de Física Geral. Volume 2. $2^{\text {a }}$ Edição. São Paulo. Nobel: 1981. 219 pp.

NUSSEnZVEIG, M. H. Curso de Física Básica, Vol. 2. $3^{\text {a }}$ Edição. São Paulo. Editora Edgard Blucher, 1981. 308 pp.

OMOTE, N. Física: $2^{\text {o }}$ grau. $3^{\text {a }}$ Edição. São Paulo. Editora Moderna. 1985. 381 pp.

OLIVEIRA, M. J. Termodinâmica. 1ª Edição. São Paulo. Editora Livraria da Física: 2005. $365 \mathrm{pp}$.

OREAR, J. Física. Livros Técnicos e Científicos Editora SA. Rio de Janeiro, 1976. 439 pp.

PARANÁ, D. N. S. Física: Termologia, Óptica, Ondulatória, volume 2. $5^{\text {a }}$ Edição. São Paulo. Editora Ática. 1998. 440 pp.

PAULI, R. U.; MAUAD, F. C.; SIMÃO, C. Física Básica, Vol. 2. Edição. São Paulo. EPU : 1979. Capítulo 1, 149 pp.

PENTEADO, P. C. M.; TORRES, C. M. A., Física - ciência e tecnologia, volume 2. $1^{\mathrm{a}}$ Edição. São Paulo. Editora Moderna: 2005. 214 pp.

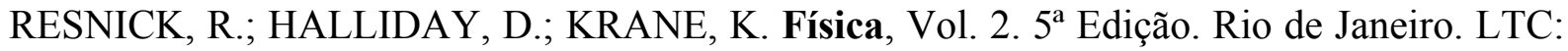
2003. $339 \mathrm{pp}$.

SEARS F. W. Física I - Mecânica, Movimento Vibratório e Calor. Rio de Janeiro. Ao Livro Técnico. 1966. 678 pp.

SEARS, F. W.; SAlinger, G. L. Termodinâmica, Teoria Cinética e Termodinâmica Estatística. $5^{\text {a }}$ Edição. São Paulo. Guanabara Dois, 1979. 403 pp.

SILVA, C. X.; FILHO, B. B. Física aula por aula: mecânica dos fluidos, termologia, óptica. $1^{a}$ Edição. São Paulo. Editora FTD: 2010. 336 pp.

SILVA, C. X.; FILHO, B. B. Física aula por aula: mecânica dos fluidos, termologia, óptica. $1^{a}$ Edição. São Paulo. Editora FTD: 2010. 336 pp. 
VAN WYlen, G. J.; SONNTAG, R. E. Fundamentos da Termodinâmica Clássica. $1^{\text {a }}$ Reimpressão. São Paulo. Edgard Blücher, 1975. 616 pp.

WYlEN, G. V.; SONNTAG, R. BORGNAKKE, C. Fundamentos da termodinâmica clássica. $4^{\mathrm{a}}$ Edição tradução da americana. São Paulo: Edgard Blucher, 2004 pp.

YAMAMOTO, K.; FUKE, L. F. Física para o Ensino Médio, volume 2. $1^{\text {a }}$ Edição. São Paulo. Editora Saraiva: 2010. 336 pp.

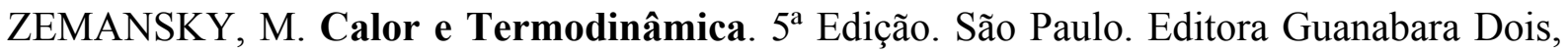
1978. $593 \mathrm{pp}$.

\section{Notas}

\footnotetext{
${ }^{\text {i }}$ Professor Pleno do Departamento de Ciência Exatas e Tecnológicas (DCET) da Universidade Estadual do Sudoeste da Bahia (UESB) e membro do Grupo de Pesquisa GDICEM, ligado ao Museu Pedagógico Casa Padre Palmeira (MP). O autor agradece aos licenciados em Física pela UESB: Jonathan Souza e Caroline Castro, coautores no resumo Correia et al (2013), por terem feito o fichamento de parte dos livros didáticos, mas, por se encontrarem em seus cursos de pós-graduação, não puderam concluir o fichamento das fontes de pesquisa, nem puderam participar da análise, da fundamentação, nem da elaboração deste artigo. E-mail para contato: Jjcorreia57@uesb.edu.br.

ii Disponível em https://www.google.com.br/?client=firefox-b\#q=energia $+\mathrm{t} \% \mathrm{C} 3 \%$ A9rmica\&gfe_rd=cr $>$. Acesso em 28/08/2016.

iii Disponível em <http://www.sofisica.com.br/conteudos/Termologia/Termometria/temperatura.php $>$. Acesso em: 28/07/2013.

${ }^{\text {iv }}$ Disponível em <http://www.brasilescola.com/fisica/temperatura-calor.htm>. Acesso em: 28/07/2013.

${ }^{v}$ Disponível em $<$ http://www.significados.com.br/temperatura/>. Acesso em: 28/07/2013.

${ }^{v i}$ Disponível em $<$ http://pt.wikipedia.org/wiki/Temperatura $>$. Acesso em: 28/07/2013.

vii Disponível em <http://blogmail.com.br/o-conceito-do-calor-e-temperatura/>. Acesso em: 28/07/2013.

viii Disponível em <http://conceito.de/temperatura $>$. Acesso em: 28/07/2013.
}

\section{Sobre o autor}

Graduado em Física, Licenciatura e Bacharelado pela Universidade Federal da Bahia; Especialista em Matemática Superior pela Fundação Educacional Severino Sombra; Mestre em Meteorologia Agrícola pela Universidade Federal de Viçosa (1990); Doutor em Física pela Universidade Federal de São Carlos (1999). É Professor Pleno do Departamento de Ciências Exatas e Tecnológicas (DCET) da Universidade Estadual do Sudoeste da Bahia (UESB) e pesquisador do Museu Pedagógico Casa Padre Palmeira (MP), Grupo de Pesquisa Didática das Ciências Experimentais e da Matemática. Professor do Mestrado Profissional Nacional em Ensino de Física (MNPEF - Polo UESB). 